\title{
Tumor marker utility and prognostic relevance of cathepsin B, cathepsin $L$, urokinase-type plasminogen activator, plasminogen activator inhibitor type-I, CEA and CA 19-9 in colorectal cancer László Herszényi*1, Fabio Farinati ${ }^{4}$, Romilda Cardin ${ }^{4}$, Gábor István², László D Molnár ${ }^{3}$, István Hritz ${ }^{1}$, Massimo De Paoli ${ }^{5}$, Mario Plebani ${ }^{5}$ and Zsolt Tulassay ${ }^{1}$
}

Address: ${ }^{12}$ nd Department of Medicine, Semmelweis University, Budapest Hungarian Academy of Science, Clinical Gastroenterology Research Unit, Budapest, Hungary, ${ }^{2}$ nd Department of Surgery, Semmelweis University, Budapest, Hungary, ${ }^{3}$ University of Technology and Economics; SocioMed Ltd., Budapest, Hungary, ${ }^{4}$ Department of Surgical \& Gastroenterological Sciences (Gastroenterology Unit), University of Padova, Padova, Italy and ${ }^{5}$ Department of Central Laboratory, University of Padova, Padova, Italy

Email: László Herszényi* - hersz@bel2.sote.hu; Fabio Farinati - fabio.farinati@unipd.it; Romilda Cardin - romilda.cardin@unipd.it; Gábor István - igabor@kut.sote.hu; László D Molnár - molnar@sociomed.hu; István Hritz - istvan.hritz@freemail.hu; Massimo De Paoli - mario.plebani@unipd.it; Mario Plebani - mario.plebani@unipd.it; Zsolt Tulassay - tulassay@bel2.sote.hu

* Corresponding author

Published: 10 July 2008

BMC Cancer 2008, 8: 194 doi:10.1 186/147|-2407-8-194
Received: 29 January 2008

Accepted: 10 July 2008

This article is available from: http://www.biomedcentral.com/I47/-2407/8//94

(C) 2008 Herszényi et al; licensee BioMed Central Ltd.

This is an Open Access article distributed under the terms of the Creative Commons Attribution License (http://creativecommons.org/licenses/by/2.0), which permits unrestricted use, distribution, and reproduction in any medium, provided the original work is properly cited.

\begin{abstract}
Background: Cathepsin B and L (CATB, CATL), urokinase-type plasminogen activator (uPA) and its inhibitor PAI-I play an important role in colorectal cancer invasion. The tumor marker utility and prognostic relevance of these proteases have not been evaluated in the same experimental setting and compared with that of CEA and CA-19-9.
\end{abstract}

Methods: Protease, CEA and CA 19-9 serum or plasma levels were determined in 56 patients with colorectal cancer, 25 patients with ulcerative colitis, 26 patients with colorectal adenomas and 35 tumor-free control patients. Protease, CEA, CA 19-9 levels have been determined by ELISA and electrochemiluminescence immunoassay, respectively; their sensitivity, specificity, diagnostic accuracy have been calculated and correlated with clinicopathological staging.

Results: The protease antigen levels were significantly higher in colorectal cancer compared with other groups. Sensitivity of PAI-I (94\%), CATB (82\%), uPA (69\%), CATL (4I\%) were higher than those of CEA or CA $19-9$ (30\% and 18\%, respectively). PAI-I, CATB and uPA demonstrated a better accuracy than CEA or CA 19-9. A combination of PAI-I with CATB or uPA exhibited the highest sensitivity value (98\%). High CATB, PAI-I, CEA and CA 19-9 levels correlated with advanced Dukes stages. CATB $(P=0.0004)$, CATL $(P=0.02)$, PAl-I $(P=0.01)$ and CA I9-9 $(P=$ $0.004)$ had a significant prognostic impact. PAI-I $(P=0.001)$, CATB $(P=0.04)$ and CA I9-9 $(P=$ $0.02)$ proved as independent prognostic variables.

Conclusion: At the time of clinical detection proteases are more sensitive indicators for colorectal cancer than the commonly used tumor markers. Determinations of CATB, CATL and PAI-I have a major prognostic impact in patients with colorectal cancer. 


\section{Background}

Colorectal cancer (CRC) is the most common gastrointestinal cancer in the Western world and it is an important cause of cancer-related death, tumor stage being generally considered the strongest prognostic factor in CRC $[1,2]$. Great effort has been dedicated to the search of sensitive and specific markers of the disease and up to now, carcinoembryonic antigen (CEA) and the gastrointestinal cancer-associated carbohydrate antigen (CA 19-9) are the most widely applied markers in gastrointestinal malignancies, e.g., CRC or pancreatic cancer [3-7].

Prediction of survival is another feature requested for tumor markers and elevated levels of both CEA and CA 19-9 have also been reported to be associated with poor prognosis in CRC [8-12]. However, because of their low sensitivity, CEA and CA 19-9 seem to be unacceptable both for screening for CRC $[3,13,14]$. Therefore, there is a need for a search of additional tumor-related antigens, eligible as tumor markers in gastrointestinal malignancies.

Tumor cells have been shown to produce and release several proteolytic enzymes, which are thought to be involved in tumor invasion and metastasis [15]. For instance, it has been observed that cathepsin B (CATB) and cathepsin L (CATL), which are cysteine proteases, the serine protease urokinase-type plasminogen activator (uPA) and its inhibitor type-1 (PAI-1) play a crucial role in this process through the destruction of various elements of the cell-surrounding extracellular matrix [1621].

Several human solid tumors have been reported to have increased levels of proteolytic enzymes in cancer tissue, strongly suggesting that proteases may be important in tumor invasion and metastasis. With respect to the gastrointestinal tract, we have previously demonstrated that proteolytic enzymes are widely distributed in gastrointestinal tissues, being implicated in processes of gastrointestinal tissue remodelling and angiogenesis [22], may have a role not only in the process of esophageal [23], gastric $[24,25]$ or colorectal cancer invasion [26], but also in the progression of gastrointestinal precancerous changes into cancer [27].

Cathepsins and components of the plasminogen activator and inhibitor system have been demonstrated in various malignant tissues, e.g., breast cancer [28-30], lung cancer [31,32], head and neck cancer [33], ovarian cancer [34], gastric cancer [35-38] or CRC [39-45] and might therefore be useful as a diagnostic tool.

With respect to the gastrointestinal tract, several studies, along with our own, have pointed to the prognostic value of proteases for survival, for instance, in gastric cancer $[24,25,38,46,47]$ and CRC [26,40,43,48-50].

A number of studies have demonstrated an elevation of serum or plasma protease levels in patients suffering from CRC [51-55], however, to our knowledge, the tumor marker utility of CATB, CATL, uPA and PAI- 1 has not been evaluated in the same experimental setting, and compared with that of the most commonly used gastrointestinal tumor markers, such as CEA and CA-19-9.

Therefore, the objective of the present study was to assess the possible clinical relevance of serum CATB, CATL and plasma UPA, PAI-1 antigen levels in the same CRC patients, compare them with the already established serum markers CEA and CA 19-9, and to evaluate any correlation between these parameters and clinicopathological and prognostic staging of CRC.

\section{Methods}

The study comprised 56 patients with CRC, who underwent colorectal resection, 29 males and 27 females, mean age $65.4 \pm 12.8$ years (range $39-86$ years) and 35 tumorfree control patients (controls) with negative gastroscopy and colonoscopy, 12 males and 23 females, mean age $46.3 \pm 13.4$ years (range $24-85$ years). For further comparison we also investigated 25 patients with ulcerative colitis (UC) without dysplasia as confirmed by colonoscopy and biopsy, 11 males and 14 females, mean age: $31.7 \pm 6.6$ years (range 22-48 years), and 26 patients with colorectal adenoma confirmed by histology after endoscopic polypectomy (samples consisted of 16 tubular adenomas with low grade dysplasia and 10 tubulovillous adenomas with high grade dysplasia), 17 males and 9 females, mean age $57.8 \pm 6.9$ years (range $47-72$ years). Informed consent was obtained from all patients. The study was approved by the Ethical Committee of Semmelweis University Budapest and Padova University.

In all instances, this was a first diagnosis of CRC, and no recurrences were taken into consideration. Patients who were undergoing chemotherapy, radiotherapy, or any other adjuvant therapy for CRC, or were expected to undergo such therapies within the study period were not included.

Clinical data of the patients and histology of tumors were registered accurately. Pathologic staging was obtained for the presence $(n=37)$ or absence $(n=19)$ of lymph node and/or distant metastases, and for differentiation (well differentiated, G1 ( $\mathrm{n}=17)$; moderately differentiated, G2 $(n=30)$; or poorly differentiated, G3 $(n=9)$. Finally, the tumors were also subgrouped according to their tumor location (colon cancer, $\mathrm{n}=38$; rectal cancer, $\mathrm{n}=18$ ). The tumors were histologically classified according to Dukes 
classification, as modified by Turnbull et al. [56]. Dukes stage A tumors were confined to the bowel wall $(\mathrm{n}=7)$; Dukes stage $\mathrm{B}$ tumors have spread beyond the wall without involving lymph nodes $(\mathrm{n}=12)$; Dukes stage $\mathrm{C}$ were associated with regional lymph node metastases $(n=23)$; and finally, Dukes stage D tumors were associated with distant metastases $(n=14)$.

\section{Blood collection}

Serum and plasma samples were collected from patients with CRC at the time of clinical tumor detection. Blood samples were collected from resting patients after a $12 \mathrm{~h}$ fasting between 8:00 and 10:00 a.m. to avoid possible influences of circadian variations on the fibrinolytic system. Blood was drawn from a cubital vein with minimal venous occlusion directly into plastic tubes prepared with sodium citrate ( $0.1 \mathrm{M}$ final concentration) as an anticoagulant to avoid platelet activation and platelet contamination. Plasma was obtained by centrifugation at $3000 \times \mathrm{g}$ for $15 \mathrm{~min}$ at $4{ }^{\circ} \mathrm{C}$, harvested and snap-frozen. The samples were stored at $-70^{\circ} \mathrm{C}$ until analysis.

\section{Determination of established tumor markers and proteases}

Serum CEA (carcinoembryonic antigen electrochemiluminescence immunoassay "ECLIA", Cobas ${ }^{\circledR}$, Roche, Diagnostics, Mannheim, Germany; cut-off limit, $4.0 \mathrm{ng} / \mathrm{ml}$ ) and serum CA 19-9 (carbohydrate electrochemiluminescence immunoassay "ECLIA", Cobas ${ }^{\circledast}$, Roche, Diagnostics, Mannheim, Germany; cut-off limit, $37.0 \mathrm{ng} / \mathrm{ml}$ ) were determined by commercially available test kits and monoclonal antibodies. Cut-off limits were taken as recommended by the manufacturers.

The assays for CATB, CATL, UPA and PAI-1 have been published elsewhere $[22,26]$. Antigen levels were measured by using the enzyme-linked immunoassay (ELISA) method as follows: briefly, cathepsin immunoassay is a solidphase ELISA based on the sandwich principle (BiAss, Diesen, Germany). Absolute quantities of CATB and CATL antigens in the serum samples were calculated from a 7 point standard curve of CATB and CATL $(0-250 \mathrm{ng} / \mathrm{ml})$. The lowest detectable concentrations were estimated at $\cong$ $1 \mathrm{ng} / \mathrm{ml}$.

The uPA antigen was determined by using the TintElize uPA-ELISA (Biopool, Umea, Sweden). The amount of uPA antigen in the plasma samples was calculated from a 6point standard curve of $\mathrm{uPA}(0-4 \mathrm{ng} / \mathrm{ml})$. The detection limit was $\cong 0.1 \mathrm{ng} / \mathrm{ml}$ for $\mathrm{uPA}$.

PAI-1 antigen quantification was performed by using the Asserachrom PAI-1 ELISA (Diagnostica Stago, Asniéressur-Seine, France). Absolute quantities of PAI-1 antigen in the plasma samples were calculated from a 7-point stand- ard curve of PAI-1 (0-250 ng/ml). The detection limit was $\cong 0.5 \mathrm{ng} / \mathrm{ml}$ for PAI-1.

\section{Statistics}

Due to the high standard deviations of some of the series, results were expressed as median levels and, after evaluation by using the Kolmogorov-Smirnov test, differences between groups were tested statistically by using the Mann-Whitney U test and the Kruskall-Wallis analysis of variance, where applicable. Spearman rank correlation test was performed to evaluate the correlation between CATB, CATL, uPA, PAI-1, CEA and CA 19-9. Differences were considered significant with $P<0.05$. The receiver operating characteristics (ROC) curves were used to determine the optimal cut-off values (with the Youden J test for overall accuracy). The areas under curve (AUCs) for all investigated biomarkers were determined according to ROC curves. The discriminative power of each biomarker for the diagnostic accuracy was tested by Fisher's exact test.

The association of proteases and CEA, CA 19-9 and survival was tested using their median values in the group of CRC. The Kaplan-Meier method was used to estimate survival probabilities, and the log-rank test was used to test equality of strata. Group-oriented curves for survival were calculated according to the Kaplan-Meier method for CATB, CATL, uPA and PAI-1 antigen levels; CEA and CA 19-9; Dukes classification; grade; tumor location; age and gender. The Cox proportional hazards model was applied for multivariate analysis. Variables were included in the multivariate analysis only if the $P$ value was less than 0.05 in the univariate analysis. The SAS software package (SAS Institute, Cary, North Carolina) was used to perform statistical analyses.

\section{Results}

Serum and plasma concentrations for CATB, CATL, uPA, PAI-1, CEA and CA 19-9 in patients with CRC, UC, colorectal adenoma and controls, expressed in $\mathrm{ng} / \mathrm{ml}$, are shown in Table 1. Significantly higher CATB, CATL, uPA and PAI-1 antigen concentrations were observed in CRC patients compared with controls, patients with UC or colorectal adenomas. No statistically significant differences were seen with respect to CEA and CA 19-9 levels. Antigen levels of CATB, CATL and PAI-1 were significantly higher in blood samples from patients with colorectal adenomas than from controls. CATB, CATL, uPA and PAI1 showed a trend towards increase in patients with UC compared with controls, but the differences were statistically not significant (Table 1).

With respect to Dukes classification, CATB, PAI-1, CEA and CA 19-9 showed the highest antigen concentrations in patients with Dukes stage D tumors (Table 2). 
Table I: Proteolytic enzymes, CEA and CA 19-9 in patients with colorectal cancer, ulcerative colitis, adenoma and controls.

\begin{tabular}{|c|c|c|c|c|c|c|}
\hline & CATB & CATL & UPA & PAI-I & CEA & CA $19-9$ \\
\hline Colorectal cancer $(n=56)$ & $\begin{array}{l}8.75 * \S \\
(2.4-39.3)\end{array}$ & $\begin{array}{l}1.10 * \S \\
(1.0-35.3)\end{array}$ & $\begin{array}{l}0.29 * \S \\
(0.1-0.79)\end{array}$ & $\begin{array}{l}52.45 * \S \\
(13.5-138.6)\end{array}$ & $\begin{array}{l}2.40 \\
(0.4-235.0)\end{array}$ & $\begin{array}{l}9.15 \\
(1.0-540.0)\end{array}$ \\
\hline $\begin{array}{l}\text { Ulcerative colitis } \\
(n=25)\end{array}$ & $\begin{array}{l}4.37 \\
(2.8-7.2)\end{array}$ & $\begin{array}{l}1.10 \\
(1.0-1.7)\end{array}$ & $\begin{array}{l}0.20 \\
(0.18-0.23)\end{array}$ & $\begin{array}{l}12.60 \\
(8.8-17.6)\end{array}$ & $\begin{array}{l}3.15 \\
(0.8-11.5)\end{array}$ & $\begin{array}{l}9.00 \\
(4.5-32.0)\end{array}$ \\
\hline Colorectal adenoma $(n=26)$ & $\begin{array}{l}4.45 \# \\
(4.2-10.3)\end{array}$ & $\begin{array}{l}1.25 \# \\
(1.0-6.5)\end{array}$ & $\begin{array}{l}0.20 \\
(0.16-0.53)\end{array}$ & $\begin{array}{l}\mid 4.05 \# \\
(10.5-65.5)\end{array}$ & $\begin{array}{l}3.55 \\
(0.7-5.7)\end{array}$ & $\begin{array}{l}10.27 \\
(3.7-41.0)\end{array}$ \\
\hline Controls $(n=35)$ & $\begin{array}{l}3.80 \\
(1.4-5.8)\end{array}$ & $\begin{array}{l}1.00 \\
(1.0-2.1)\end{array}$ & $\begin{array}{l}0.19 \\
(0.16-0.27)\end{array}$ & $\begin{array}{l}10.70 \\
(1.87-23.8)\end{array}$ & $\begin{array}{l}2.90 \\
(0.8-18.9)\end{array}$ & $\begin{array}{l}8.90 \\
(1.27-47.4)\end{array}$ \\
\hline Kruskall-Wallis analysis of variance ( $P$ value) & $P<0.0001$ & $P<0.0001$ & $P<0.0001$ & $P<0.0001$ & $P=N S$ & $P=N S$ \\
\hline
\end{tabular}

Cathepsin B, cathepsin L, urokinase-type plasminogen activator, plasminogen activator inhibitor type-I, CEA and CA 19-9 levels in patients with colorectal cancer $(n=56)$, ulcerative colitis $(n=25)$, colorectal adenoma $(n=26)$ and controls $(n=35)$ expressed in $n g / m l(m e d i a n$ values and range)

Statistics:

* Colorectal cancer: $P<0.001$ vs Controls

$\S$ Colorectal cancer: $P<0.05$ vs Ulcerative colitis and Colorectal adenoma \# Colorectal adenoma: $P<0.001$ vs Controls

Abbreviations: CATB: cathepsin B; CATL: cathepsin L; uPA: urokinase-type plasminogen activator, PAI-I: plasminogen activator inhibitor type-I;

CEA: carcinoembryonic antigen; CA 19-9: carbohydrate antigen 19-9; NS: not significant

Antigen levels of CATB, CATL, uPA, PAI-1 and CEA, CA 19-9 levels showed a trend toward higher levels in patients with colon cancer compared to patients with rectal cancer, but the differences were not statistically significant (data not shown). No statistically significant changes were observed in association with tumor grade, age or gender (data not shown).

The receiver operating characteristics (ROC) curves were used to determine the optimal cut-off values (with the Youden J test for overall accuracy). The optimal cut-off value for CATB was $4.60 \mathrm{ng} / \mathrm{ml}$ (Youden $J=0.68$ ), the cutoff for CATL was placed at $1.12 \mathrm{ng} / \mathrm{ml}$ (Youden $J=0.25$ ). The optimal selected cut-off values for uPA and PAI-1 were $0.21 \mathrm{ng} / \mathrm{ml}$ (Youden $J=0.53$ ) and $18.90 \mathrm{ng} / \mathrm{ml}$ (Youden $J=0.75$ ), respectively. Cut-off limits for CEA (4.0 $\mathrm{ng} / \mathrm{ml})$ and CA $19-9(37.0 \mathrm{ng} / \mathrm{ml})$ were taken as recommended by the manufacturers.

Sensitivity was calculated as the percentage of individuals in the tumor groups (test-positive tumor patients) who showed concentrations of tumor markers above the respective cut-off limits. Specificity was calculated as the percentage of test-negative, non-tumor individuals, which could be either healthy individuals (controls), those with UC or patients with colorectal adenomas.

Table 2: Proteolytic enzymes, CEA and CA $19-9$ in correlation with Dukes classification.

\begin{tabular}{|c|c|c|c|c|c|c|}
\hline Stage & CATB & CATL & uPA & PAI-I & CEA & CA $19-9$ \\
\hline DUKES A $(n=7)$ & $\begin{array}{l}4.50 \\
(2.4-37.3)\end{array}$ & $\begin{array}{l}1.10 \\
(1.0-35.3)\end{array}$ & $\begin{array}{l}0.30 \\
(0.2-0.62)\end{array}$ & $\begin{array}{l}32.81 \\
(17.2-66.7)\end{array}$ & $\begin{array}{l}3.00 \\
(0.6-3.4)\end{array}$ & $\begin{array}{l}6.80 \\
(3.0-11.5)\end{array}$ \\
\hline DUKES B $(n=12)$ & $\begin{array}{l}6.75 \\
(3.2-23.8)\end{array}$ & $\begin{array}{l}1.00 \\
(1.0-12.3)\end{array}$ & $\begin{array}{l}0.29 \\
(0.1-0.79)\end{array}$ & $\begin{array}{l}39.09 \\
(13.5-108.1)\end{array}$ & $\begin{array}{l}2.00 \\
(0.6-21.1)\end{array}$ & $\begin{array}{l}7.65 \\
(1.0-35.0)\end{array}$ \\
\hline DUKES C $(n=23)$ & $\begin{array}{l}8.60 \\
(3.6-35.7)\end{array}$ & $\begin{array}{l}1.10 \\
(1.0-34.1)\end{array}$ & $\begin{array}{l}0.26 \\
(0.1-0.79)\end{array}$ & $\begin{array}{l}52.54 \\
(13.8-126.4)\end{array}$ & $\begin{array}{l}2.20 \\
(0.4-235.0)\end{array}$ & $\begin{array}{l}9.20 \\
(1.0-78.6)\end{array}$ \\
\hline DUKES D $(n=14)$ & $\begin{array}{l}24.25 * \S \\
(9.2-39.3)\end{array}$ & $\begin{array}{l}4.55 \\
(1.0-35.2)\end{array}$ & $\begin{array}{l}0.29 \\
(0.12-0.42)\end{array}$ & $\begin{array}{l}82.03 * * \\
(38.7-138.6)\end{array}$ & $\begin{array}{l}8.30 \# \\
(1.9-74.6)\end{array}$ & $\begin{array}{l}35.85 * * \\
(4.6-540.0)\end{array}$ \\
\hline Kruskall-Wallis analysis of variance ( $P$ value) & $P=0.0002$ & $P=N S$ & $P=N S$ & $P=0.01$ & $P=0.003$ & $P=0.001$ \\
\hline
\end{tabular}

Cathepsin B, cathepsin L, urokinase-type plasminogen activator, plasminogen activator inhibitor type-I, CEA and CA 19-9 levels in association with Dukes classification of colorectal cancer expressed in $\mathrm{ng} / \mathrm{ml}$ (median values and range)

Statistics:

$* P<0.01$, Dukes D vs Dukes A and B

$\S P<0.05$, Dukes $D$ vs Dukes $C$

**P $<<0.05$, Dukes $D$ vs Dukes $A, B$ and $C$

$\# P<0.01$, Dukes $D$ vs Dukes $A, B$ and $C$

Abbreviations: DUKES A: Dukes stage A; DUKES B: Dukes stage B; DUKES C: Dukes stage C; DUKES D: Dukes stage D; CATB: cathepsin B; CATL: cathepsin L; uPA: urokinase-type plasminogen activator, PAI-I: plasminogen activator inhibitor type-I; CEA: carcinoembryonic antigen; CA 19-9: carbohydrate antigen 19-9; NS: not significant 
When proteases, CEA and CA 19-9 were used as single markers, considering the above mentioned optimal cutoff values, sensitivity of PAI-1 (94\%), CATB (82\%), uPA $(69 \%)$ and CATL $(41 \%)$ were more indicative for CRC than CEA or CA $19-9$ (30\% and $18 \%$, respectively). Specificity of CATB (88\%) and PAI-1 (84\%) was in the same range than that of the established markers (CA 19-9: 93\%, CEA: 89\%) (Table 3).

PPV (probability of detection a CRC by a positive test) and NPV values (probability of exclusion of a CRC suspicion by a negative test) are post-test probabilities and thus strongly dependent on the pre-test probability (positive prevalence) reflecting the percentage of tumor patients in all patient groups investigated, i.e. $56 / 142=39 \%$, and negative prevalence reflecting the percentage of nontumor individuals in all patient groups investigated, i.e. $86 / 142=61 \%$. The comparison of positive prevalence with PPV and negative prevalence with NPV allows to judge the utility of PPV and NPV values in relation to a probability by chance, i.e. they should differ from the prevalence by at least $20 \%$. According to this, the PPV values were of relevance for CATB, uPA, PAI-1, CEA and CA 19-9, and less for CATL; inversely, the NPV values were of relevance for CATB, PAI-1, uPA, but not at all for CATL, CEA and CA 19-9 (Table 3).

PAI-1, CATB and uPA demonstrated a better diagnostic accuracy than CEA, CATL or CA 19-9, PAI-1 showed the highest accuracy (Table 3).

The clinical relevance of the different markers is demonstrated by ROC curves. The ROC curves of PAI- 1 and CATB were located closer to the theoretical 100\% sensitivity and specificity values than the ROC curves of other investigated markers (Figure 1).
Table 4 summarizes the areas under curve (AUCs) for all investigated biomarkers. Again, PAI-1 and CATB demonstrated the highest accuracy and the best discriminative power.

Sensitivity and specificity values during multiparametric tumor marker analysis are given in Table 5. When two markers were determined in identical blood samples, combined sensitivity values disclosed the superiority of the combination of PAI-1 together with CATB or uPA (both markers correctly test-positive for tumor patients in $78 \%$ and $64 \%$, respectively; one of two markers correctly test-positive in the tumor group in $98 \%$ ) as compared to the combinations of all other markers, including proteases with CEA or CA 19-9, or CEA with CA 19-9. The sensitivity of CEA or CA 19-9 in combination with a protease antigen level was more indicative for CRC than CEA or CA 19-9 alone (when one of two markers was correctly test-positive). The combined use of three markers (one protease in combination with CEA and CA 19-9) did not lead to a further increase in sensitivity.

The specificity of CEA or CA 19-9 in combination with a protease antigen level or the combination of CEA with CA 19-9 was more indicative for correctly negative patients than CEA or CA 19-9 alone (when one of two markers was correctly test-negative for non-tumor patients). When two protease levels were considered, combined specificity values (one of two markers correctly test-negative for nontumor group) were also higher than specificity of CATB, CATL, uPA or PAI-1 as a single marker. The combined use of three markers (one protease in combination with CEA and CA 19-9) did not lead to a further increase in specificity (Table 5).

Table 3: Diagnostic accuracy of proteolytic enzymes, CEA and CA 19-9 in colorectal cancer.

\begin{tabular}{|c|c|c|c|c|c|c|}
\hline & CATB & CATL & uPA & PAI-I & CEA & CA $19-9$ \\
\hline Cut-off & $(4.60)$ & $(1.12)$ & $(0.21)$ & $(18.90)$ & $(4.0)$ & $(37.0)$ \\
\hline Sensitivity (\%) & 82 & 41 & 69 & 94 & 30 & 18 \\
\hline Specificity (\%) & 88 & 80 & 82 & 84 & 89 & 93 \\
\hline PPV (\%) & 82 & 58 & 72 & 79 & 65 & 62 \\
\hline PPV-Positive Prevalence (\%) & 43 & 19 & 33 & 40 & 26 & 23 \\
\hline NPV (\%) & 88 & 68 & 80 & 96 & 66 & 63 \\
\hline NPV-Negative Prevalence (\%) & 27 & 7 & 19 & 35 & 5 & 2 \\
\hline Accuracy (\%) & 86 & 65 & 77 & 88 & 66 & 63 \\
\hline Fisher's Exact Test & $P<0.0001$ & $P=0.008$ & $P<0.0001$ & $P<0.0001$ & $P=0.004$ & $P=0.06$ \\
\hline
\end{tabular}

Sensitivity, specificity, positive predictive value, negative predictive value and accuracy of cathepsin B, cathepsin L, urokinase-type plasminogen activator, plasminogen activator inhibitor type-I, CEA and CA 19-9 in colorectal cancer

Abbreviations: PPV: Positive predictive value; NPV: Negative predictive value; CATB: cathepsin B; CATL: cathepsin L; uPA: urokinase-type plasminogen activator, PAI-I: plasminogen activator inhibitor type-I; CEA: carcinoembryonic antigen; CA 19-9: carbohydrate antigen 19-9; Cut-off: cut-off values expressed in $\mathrm{ng} / \mathrm{ml}$; Positive Prevalence: the percentage of tumor patients in all patient groups investigated, i.e. $56 / \mathrm{I} 42=39 \%$; Negative Prevalence: the percentage of non-tumor individuals in all patient groups investigated, i.e. 86/I42 = 61\%; PPV-Positive Prevalence: the difference between PPV and positive prevalence; NPV-Negative Prevalence: the difference between NPV and negative prevalence 


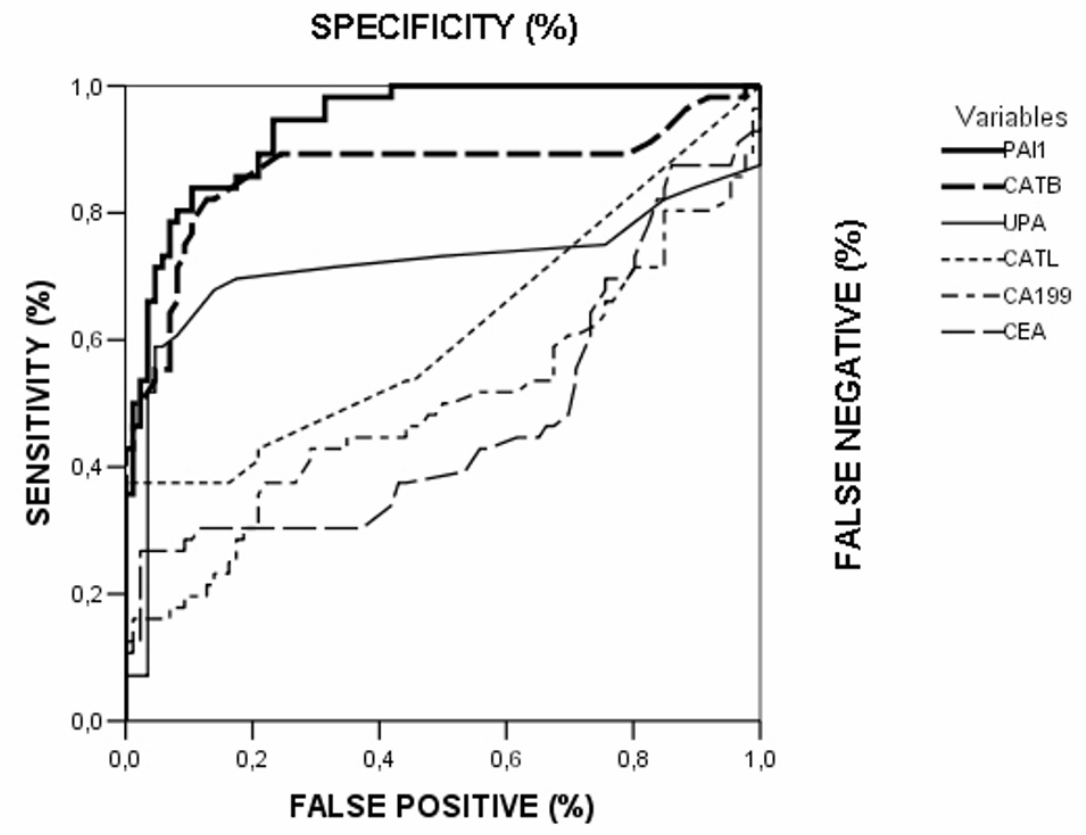

Figure I

ROC curves for proteolytic enzymes, CEA and CA I 9-9 in patients with colorectal cancer. The clinical relevance of cathepsin B (CATB), cathepsin L (CATL), urokinase-type plasminogen activator (uPA), plasminogen activator inhibitor typeI (PAI-I), CEA and CA I9-9 was compared by establishing ROC curves. The ROC curves of PAI-I and CATB were located closer to the theoretical $100 \%$ sensitivity and specificity values than the ROC curves of other investigated markers.

Table 6 demonstrates associations between proteases and CEA/CA 19-9, determined in identical blood samples obtained from CRC patients. When correlation analysis was assessed between proteases, CATB significantly correlated with CATL, uPA and PAI-1. Significant correlations were also found between the antigen levels of PAI-1 and CATL, and finally PAI-1 and uPA. CEA and CA 19-9 also

Table 4: The areas under curve for proteolytic enzymes, CEA and CA 19-9 according to ROC curves.

\begin{tabular}{lccc}
\hline Variable & AUC & Lower limit & Upper limit \\
\hline PAI-I & 0.9385 & 0.9025 & 0.9744 \\
CATB & 0.8665 & 0.7934 & 0.9397 \\
uPA & 0.7143 & 0.6091 & 0.8196 \\
CATL & 0.6173 & 0.5158 & 0.7188 \\
CA 19-9 & 0.4990 & 0.3937 & 0.6043 \\
CEA & 0.4748 & 0.3690 & 0.5807 \\
\hline
\end{tabular}

Determination of areas under curve for cathepsin B, cathepsin L, urokinase-type plasminogen activator, plasminogen activator inhibitor type-I, CEA and CA 19-9 according to ROC curves allowing to evaluate their accuracy and different discriminative power Abbreviations: AUC: area under curve; CATB: cathepsin B; CATL: cathepsin L; uPA: urokinase-type plasminogen activator, PAI-I: plasminogen activator inhibitor type- I; CEA: carcinoembryonic antigen; CA 19-9: carbohydrate antigen 19-9; ROC: receiver operating characteristics significantly correlated in the group of CRC. When Spearman rank correlation test was performed in CRC between CEA, CA 19-9 and proteases, both CEA and CA 19-9 significantly correlated with CATB and PAI-1.

The CRC patients were enrolled in a follow-up protocol. The follow-up ended at the event of death or, when the patient was still alive, at the last follow-up date. Patients were followed either directly or through their attending physicians. Thirty-five patients $(62.5 \%)$ died of tumor recurrence. Their median survival was 32 months (95\% CL, 23-38; range, 7-78 months). At the end of follow-up period, 21 patients (37.5\%) were still alive; their median follow-up was 86 months (95\% CL, 85-91; range 76-96 months). The median survival time calculated for all patients was 45 months (95\% CL, 43-61; range 7-96 months). The median survival for the subgroup of patients who underwent curative resection (Dukes A-C) was 77 months (95\%CL, 56-73, range 7-96 months), whereas it was 14 months in the remaining group of patients with Dukes D tumors (95\%CL, 11-19; range, 8-36 months; $P<0.001)$.

No statistically significant difference was observed in association with tumor location (median survival period for patients with colon cancer and rectal cancer: 43 months, 
Table 5: Multiparametric tumor marker analysis in colorectal cancer.

\begin{tabular}{|c|c|c|c|c|}
\hline \multirow[b]{3}{*}{ Two markers } & \multicolumn{4}{|c|}{ Colorectal cancer } \\
\hline & \multicolumn{2}{|c|}{ Sensitivity } & \multicolumn{2}{|c|}{ Specificity } \\
\hline & Both positive & Either positive & Both negative & Either negative \\
\hline PAI-I + CATB & $78 \%$ & $98 \%$ & $73 \%$ & $98 \%$ \\
\hline PAI-I + uPA & $64 \%$ & $98 \%$ & $67 \%$ & $98 \%$ \\
\hline PAI-I + CATL & $39 \%$ & $96 \%$ & $67 \%$ & $96 \%$ \\
\hline CATB + uPA & $55 \%$ & $95 \%$ & $79 \%$ & $87 \%$ \\
\hline CATB + CATL & $41 \%$ & $84 \%$ & $75 \%$ & $94 \%$ \\
\hline CATL + uPA & $30 \%$ & $80 \%$ & $72 \%$ & $90 \%$ \\
\hline PAI-I + CEA & $30 \%$ & $96 \%$ & $73 \%$ & $98 \%$ \\
\hline CATB + CEA & $28 \%$ & $84 \%$ & $83 \%$ & $95 \%$ \\
\hline $\mathrm{uPA}+\mathrm{CEA}$ & $20 \%$ & $80 \%$ & $76 \%$ & $95 \%$ \\
\hline CATL + CEA & $20 \%$ & $52 \%$ & $75 \%$ & $94 \%$ \\
\hline PAl-I + CA 19-9 & $18 \%$ & $96 \%$ & $77 \%$ & $98 \%$ \\
\hline CATB + CA $19-9$ & $16 \%$ & $84 \%$ & $86 \%$ & $97 \%$ \\
\hline uPA + CA 19-9 & $14 \%$ & $73 \%$ & $80 \%$ & $95 \%$ \\
\hline CATL + CA $19-9$ & $11 \%$ & $48 \%$ & $78 \%$ & $95 \%$ \\
\hline CEA + CA 19-9 & $16 \%$ & $32 \%$ & $86 \%$ & $97 \%$ \\
\hline
\end{tabular}

\begin{tabular}{|c|c|c|c|c|}
\hline Three markers & All positive & Either positive & All negative & Either negative \\
\hline PAI-I +CEA +CA I9-9 & $16 \%$ & $96 \%$ & $71 \%$ & $98 \%$ \\
\hline CATB +CEA +CA $19-9$ & $14 \%$ & $84 \%$ & $80 \%$ & $97 \%$ \\
\hline uPA +CEA +CA 19-9 & $12 \%$ & $80 \%$ & $74 \%$ & $97 \%$ \\
\hline CATL +CEA +CA $19-9$ & $9 \%$ & $52 \%$ & $74 \%$ & $97 \%$ \\
\hline
\end{tabular}

Sensitivity and specificity values of cathepsin B, cathepsin L, urokinase-type plasminogen activator, plasminogen activator inhibitor type-I, CEA and CA 19-9 during multiparametric tumor marker analysis in colorectal cancer $(n=56)$

CATB: cathepsin B; CATL: cathepsin L; uPA: urokinase-type plasminogen activator, PAI-I: plasminogen activator inhibitor type-I; CEA: carcinoembryonic antigen; CA 19-9: carbohydrate antigen 19-9;

Both: both markers correctly positive or negative; All: all three markers correctly positive or negative; Either: one of two/or three markers correctly positive or negative

95\%CL, 40-62; range, 8-96 months, and 55 months, 95\%CL, 37-70, range, 7-94 months, respectively).

The association of proteolytic enzymes and CEA, CEA-19 and survival was tested using their median values in the group of CRC (CATB: $8.75 \mathrm{ng} / \mathrm{ml}$; CATL: $1.1 \mathrm{ng} / \mathrm{ml}$; uPA: $0.29 \mathrm{ng} / \mathrm{ml}$; PAI-1: $52.45 \mathrm{ng} / \mathrm{ml}$; CEA: $2.40 \mathrm{ng} / \mathrm{ml}$; CA 199: $9.15 \mathrm{ng} / \mathrm{ml})$.

In univariate survival analysis, CATB antigen levels $(P=$ $0.0004)$ (Figure 2A), CATL antigen levels $(P=0.02)$ (Figure 2B), PAI-1 antigen levels $(P=0.01)$ (Figure 2C), CA 19-9 $(P=0.004)$, and Dukes classification $(P<0.0001)$ were significantly correlated with survival. No significant correlation was observed with respect to uPA antigen levels, CEA, tumor grade, tumor location, age and gender. To determine the independent value of these prognostic fac- tors, multivariate analysis was performed. Variables were included in the multivariate analysis only if the $P$ value was less than 0.05 in the univariate analysis. In the multivariate statistical analysis all parameters - including Dukes classification, PAI-1, CATB, CATL and CA 19-9 were tested in one model. According to this, significant independent prognostic information was obtained from Dukes classification $(P=0.004)$, PAI-1 $(P=0.001)$, CATB $(P=0.04)$ and CA $19-9(P=0.02)$, but not from CATL. Analysed as continuous variables in the Cox model, PAI-1 (HR 2.22, $P=0.001$ ), CATB (HR 2.09, $P=0.04$ ) and CA 19-9 (HR 1.98, $P=0.02$ ) were found to be Dukes-independent prognostic factors (Table 7).

\section{Discussion}

Among several tumor markers, that are suggested to correlate with the presence and prognosis of CRC, CEA and CA 
Table 6: Correlation analysis of proteolytic enzymes, CEA and CA 19-9 in colorectal cancer.

\begin{tabular}{lcc}
\hline & \multicolumn{2}{c}{ Colorectal cancer } \\
& $P$ value & (correlation coefficient) \\
\hline CATB/CATL & $P=0.0001$ & $(r S=0.67)$ \\
CATB/uPA & $P=0.03$ & $(r S=0.28)$ \\
CATB/PAI-I & $P=0.04$ & $(r S=0.27)$ \\
CATL/uPA & $P=0.11$ & $(r S=0.21)$ \\
PAI-1/CATL & $P=0.03$ & $(r S=0.27)$ \\
PAI-1/uPA & $P=0.001$ & $(r S=0.41)$ \\
& & \\
CEA/CA 19-9 & $P=0.0003$ & $(r S=0.46)$ \\
CEA/CATB & $P=0.002$ & $(r S=0.40)$ \\
CEA/CATL & $P=0.06$ & $(r S=0.25)$ \\
CEA/uPA & $P=0.70$ & $(r S=0.05)$ \\
CEA/PAI-I & $P=0.002$ & $(r S=0.40)$ \\
CA 19-9/CATB & $P=0.005$ & $(r S=0.36)$ \\
CA 19-9/CATL & $P=0.33$ & $(r S=0.13)$ \\
CA 19-9/uPA & $P=0.46$ & $(r S=0.10)$ \\
CA 19-9/PAI-I & $P=0.005$ & $(r S=0.36)$ \\
\hline
\end{tabular}

Correlation of cathepsin B, cathepsin L, urokinase-type plasminogen activator, plasminogen activator inhibitor type-I, CEA and CA 19-9 in patients with colorectal cancer $(n=56)$

Abbreviations: CATB: cathepsin B; CATL: cathepsin L; uPA: urokinasetype plasminogen activator, PAI-I: plasminogen activator inhibitor type- I; CEA: carcinoembryonic antigen; CA 19-9: carbohydrate antigen 19-9; rS: Spearman rank correlation coefficient
19-9 are the most widely accepted [3-7]. However, the rather low sensitivity of serum CEA or CA 19-9, their secretion rates from individual tumors and nonspecific elevations reduce their tumor marker utility and indicate the need for additional more reliable markers for CRC.

Proteolytic mechanisms, such as those that depend on cysteine (CATB, CATL) and serine proteases (uPA, PAI-1) are recognized as crucial factors in tumor invasion and metastasis. Cysteine proteases (CATB, CATL) play an important role in this process through the destruction of various elements of cell-surrounding extracellular matrix, whereas uPA appears to promote invasion through a plasmin-mediated degradation of extracellular matrix proteins. Active uPA catalyses the conversion from plasminogen to plasmin, that is a potent activator of several metalloproteinase proenzymes, such as prostromelysin, procollagenase, and progelatinase. Beyond its direct proteolytic capacity, CATB has been shown also to activate the pro-urokinase-type plasminogen activator (pro-uPA). PAI-1 under normal physiologic conditions inhibits uPA by forming a covalent enzyme-inhibitor complex. However, the exact role of PAI-1 in tumor biology is not well established. It has been suggested that PAI-1 may represent a specific protein of transformed malignant tissue and it has also been claimed that PAI-1 may serve to protect cancer tissue against the proteolytic degradation triggered by the tumor on surrounding normal tissue. Furthermore, the inhibitor has a role in angiogenesis,

Table 7: Univariate and multivariate analysis of survival in patients with colorectal cancer.

\begin{tabular}{|c|c|c|c|c|}
\hline \multirow[b]{3}{*}{ Variable } & \multirow{3}{*}{$\begin{array}{c}\text { Univariate analysis } \\
\text { Log-Rank Test } \\
\text { P value }\end{array}$} & \multicolumn{3}{|c|}{ Multivariate analysis } \\
\hline & & \multicolumn{3}{|c|}{ Cox Proportional Hazards Model } \\
\hline & & $P$ value & HR & $(95 \% \mathrm{CL})$ \\
\hline Dukes & $<0.0001$ & 0.004 & 1.88 & $(1.22-2.89)$ \\
\hline PAI-I & 0.012 & 0.001 & 2.22 & $(1.21-4.06)$ \\
\hline САTB & 0.0004 & 0.042 & 2.09 & $(1.02-4.26)$ \\
\hline CATL & 0.021 & 0.639 & 1.17 & $(0.60-2.29)$ \\
\hline CA $19-9$ & 0.004 & 0.024 & 1.98 & $(1.09-3.58)$ \\
\hline uPA & 0.369 & & & \\
\hline CEA & 0.159 & & & \\
\hline Grade & 0.420 & & & \\
\hline Location & 0.566 & & & \\
\hline Age & 0.247 & & & \\
\hline Gender & 0.122 & & & \\
\hline
\end{tabular}

Univariate analysis including Dukes classification, cathepsin B, cathepsin L, urokinase-type plasminogen activator, plasminogen activator inhibitor type-I, CEA, CA 19-9, tumor grade, tumor location, age, and gender. Variables were included in the multivariate analysis only if the $P$ value was less than 0.05 in the univariate analysis. In the multivariate statistical analysis all parameters -including Dukes classification, PAI-I, CATB, CATL and CA 19-9 - were tested in one model.

Abbreviations: Dukes: Dukes classification; CATB: cathepsin B; CATL: cathepsin L; uPA: urokinase-type plasminogen activator, PAI-I: plasminogen activator inhibitor type-I; CEA: carcinoembryonic antigen; CA 19-9: carbohydrate antigen 19-9; Grade: tumor grade (differentiation); Location: tumor location; HR: Hazard ratio; 95\% CL: 95\% Hazard ratio confidence limits 
A

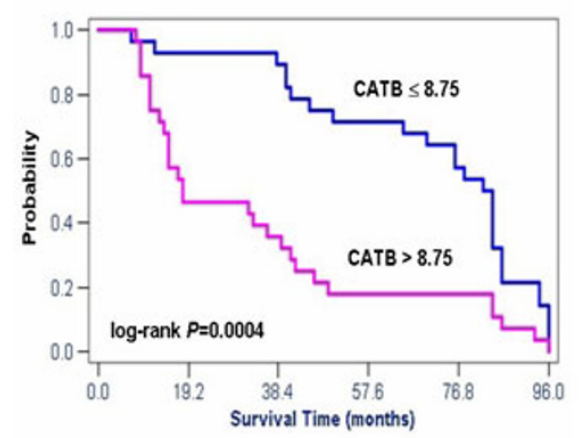

B

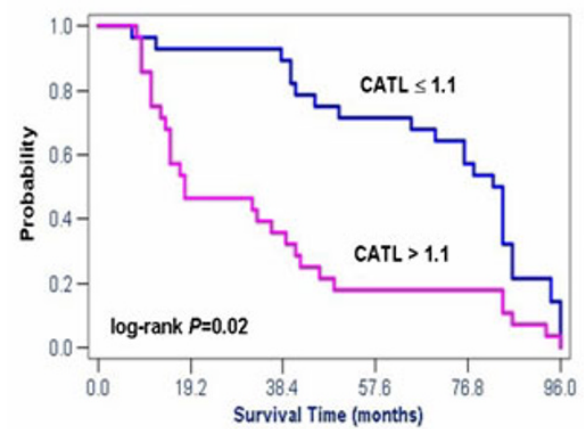

$\mathrm{C}$

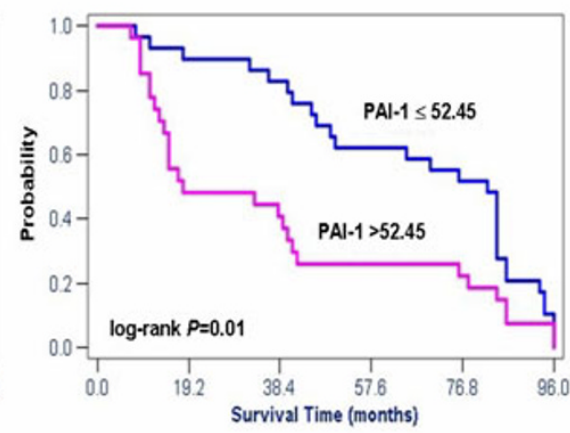

Figure 2

Survival curves stratified by cathepsin B, cathepsin $L$ and plasminogen activator inhibitor type-I in colorectal cancer. The association of preoperative serum cathepsin B (CATB), cathepsin L (CATL) and plasma plasminogen activator inhibitor type-I (PAI-I) antigen levels and overall survival in patients with primary colorectal carcinoma $(C R C)(n=56)$. By using the median values of CATB, CATL and PAI-I the patients were divided into two groups. High antigen levels identified patients with shorter survival and those who were at higher risk of death. Group-oriented curves for survival were calculated according to the Kaplan-Meier method. The $P$ values are shown in the figure. A. CATB in sera of patients with CRC (CATB median as a cut-off value, $8.75 \mathrm{ng} / \mathrm{ml}$ ). B. CATL in sera of patients with CRC (CATL median as a cut-off value, I.I ng/ml). C. PAI-I in plasma of patients with CRC (PAI-I median as a cut-off value, $52.45 \mathrm{ng} / \mathrm{ml}$ ).

which has an important part to play in tumor spread [1521].

Several studies have suggested the potential impact of proteases as tumor markers in CRC [51-55]. Given the lack in the literature for a comparison of the tumor marker utility and possible prognostic relevance of cathepsins (CATB, CATL) and the UPA/PAI-1 system in the same experimental setting, in the current study, we surveyed the behavior of CATB, CATL, UPA, PAI-1 in CRC and compared with commonly used gastrointestinal tumor markers CEA and CA 19-9, and then evaluated any correlation between these parameters and the clinicopathological staging of CRC.

In our study, antigen levels of proteases were measured by using ELISA method. Most ELISAs used to measure uPA and PAI-1 levels generally are unable to distinguish between the different forms of UPA and PAI-1; thus, the overall ELISA signal results from a mixture of substances (e.g., pro-, active, and complexed forms of the analyte). Therefore, it has been proposed that the levels of uPA:PAI1 complex may provide additional valuable predictive information. Indeed, it has been demonstrated by Manders et al. that increased uPA:PAI-1 complex levels, like uPA and PAI-1 levels separately, were significantly associated with poor overall survival, moreover, the expression of uPA:PAI-1 complex independently predicted the efficacy of adjuvant chemotherapy in patients with primary breast cancer [29].
We confirm the previous observations that preoperative serum CATB [51,53,55], plasma uPA [52] and PAI-1 [54] concentrations are significantly higher in CRC than those found in control non-cancer patients. In addition, with respect to cathepsins, we demonstrated that not only CATB but also CATL is elevated in sera of CRC patients. Interestingly, no statistically significant differences were seen in association with CEA and CA 19-9.

We demonstrate for the first time that antigen levels of CATB, CATL and PAI-1 were significantly higher in blood samples from patients with colorectal adenomas compared to the controls. Thus our results with previous results obtained in colorectal tissues $[42,57]$ confirm that CATB, CATL and PAI-1 may be involved in the progression from premalignant colorectal adenoma into CRC.

When proteases, CEA and CA 19-9 were used as single markers, we found that sensitivity of PAI-1 (94\%), CATB (82\%), uPA (69\%) and CATL (41\%) were more indicative for CRC than CEA or CA $19-9$ (30\% and 18\%, respectively). Our data are in agreement with observations of Huber et al. [52]. They have reported that sensitivity of uPA was superior to that of the established markers (75.5\% vs. $51.5 \%$ of both CEA and CA 19-9). Specificity of CATB and PAI- 1 were in the same range than that of CA 19-9 or CEA. PAI-1, CATB and uPA demonstrated a better accuracy than CEA or CA 19-9, PAI-1 showing the highest accuracy. 
It has been suggested that a combined use of different tumor-associated antigens might be of better clinical value for the detection and follow-up of various cancers. The simultaneous determination of several markers led to a greater sensitivity in our group of CRC patients: PAI-1 combined with CATB or UPA was superior compared to the combination of all other markers, including proteases with CEA or CA 19-9. In addition, the sensitivity of CEA or CA 19-9 in combination with a protease antigen level was more indicative for CRC than CEA or CA 19-9 alone. Furthermore, during the multiparametric tumor marker analysis, the combined use of two markers in all combinations led to a further increase in specificity.

This observation was confirmed by the data we obtained by examining the correlation of the investigated parameters with Dukes staging, an established predictor of prognosis. While CATL and uPA did not show any correlation with the stage, CATB, PAI-1, CEA and CA 19-9 did show a significant increase in patients with advanced stage.

Increased pre-operative serum levels of CEA and CA 19-9 have been already shown to correlate with shorter disease free and overall survival [8-12] It has been also previously reported that higher serum levels of СATB $[51,53,55]$ and plasma levels of PAI-1 [54] are correlated with advanced tumor stage and shorter survival in CRC. According to our experience, in a univariate survival analysis not only CATB and PAI-1, but also CATL antigen levels were significant in prediction of survival. High serum CATB, CATL and plasma PAI-1 antigen levels indeed identified patients with shorter survival and those who were at higher risk of death. In addition, PAI-1 and CATB proved as independent predictor variables in a multivariate statistical analysis. With respect to the commonly used tumor markers, only CA 19-9 correlated significantly with survival and was found to be independent prognostic factor. In our series no significant correlation was observed in association with respect to UPA antigen levels, CEA, tumor grade, tumor location, age and gender.

The data in the literature and our own on patient's survival suggest that serum CATB, CATL and plasma PAI-1 levels might be more useful than the traditionally used tumor markers. Our results are in full agreement with recent guidelines regarding the use of CEA or CA 19-9 in CRC. According to these guideline recommendations, inadequate sensitivity severely limits the value of CEA for the diagnosis of CRC, therefore CEA should not be used to screen for early CRC. Further, data are insufficient to support the use of CEA to determine whether to treat a patient with adjuvant chemotherapy. On the other hand, CEA is the marker of choice for monitoring metastatic CRC during systemic therapy. With respect to CA 19-9, although preoperative elevated levels may provide prog- nostic information, present data are insufficient to recommend CA 19-9 for screening, diagnosis, surveillance or monitoring treatment of patients with CRC $[58,59]$.

We report for the first time that serum CATB antigen levels significantly correlate with plasma UPA and PAI-1 levels in CRC, and a significant correlation is also found between the antigen levels of CATL and PAI-1. This confirms previous data obtained in gastrointestinal cancerous tissues on a concomitant activation of these systems $[21,24,26,27]$, while the simultaneous up-regulation of cysteine and serine proteases in CRC strongly confirms the role of cathepsins and the UPA/PAI-1 system in the biology of CRC.

\section{Conclusion}

In summary, our data provide evidence for possible clinical application of the determination of CATB, CATL, UPA and PAI-1 in addition to CEA and CA 19-9 in identical blood samples in patients with CRC. At the time of clinical presentation, proteases are more sensitive indicators of diagnosis than the most commonly used markers CEA and CA 19-9. Even though the benefits of multiparametric tumor markers analyses are highly questionable, the levels of sensitivity and specificity reached in our study seem to open the door to such an approach in CRC. On the other hand, we demonstrate the clear-cut prognostic impact of serum CATB, CATL and plasma PAI-1 antigen levels for patients with CRC. Moreover, in multivariate analysis, PAI-1 and CATB were strong and independent prognostic factors in CRC. Finally, our results suggest that CATB, CATL and PAI-1 may have a crucial role not only in the invasive process of cancer, but also in the progression of colorectal precancerous lesions into cancer.

\section{Abbreviations}

AUC: area under curve; CATB: cathepsin B; CATL: cathepsin L; CEA: carcinoembryonic antigen; CA 19-9: carbohydrate antigen 19-9; 95\%CL: 95\% confidence limits; ELISA: enzyme-linked immunoassay; HR: Hazard ratio; PAI-1: plasminogen activator inhibitor type-1; pro-uPA: prourokinase-type plasminogen activator; ROC: receiver operating characteristics; rS: Spearman rank correlation coefficient; uPA: urokinase-type plasminogen activator.

\section{Competing interests}

The authors declare that they have no competing interests. There is no conflict of interest, financially or personally, with other people or organization that could inappropriately influence our work.

\section{Authors' contributions}

LH had the initial idea for the study, participated in the study design of the study, performed statistical analysis, generated experimental data and drafted the manuscript. FF participated in the review and commentary of docu- 
ments relative to the study and manuscript editing. RC, GI, MDP and MP generated experimental data. LDM performed statistical analysis. IH performed statistical analysis and drafted the manuscript. ZT participated in the design and coordination of the study. Each author participated in the study to a significant extent. All authors read and approved the final manuscript.

\section{Acknowledgements}

This study was presented partly at the Annual Meeting of American Gastroenterological Association, Digestive Disease Week, in Los Angeles, May 2002, and published in abstract form (Gastroenterology 2002; I22: A 486).

\section{References}

I. Berger AC, Sigurdson ER, LeVoyer T, Hanlon A, Mayer RJ, Macdonalds JS, Berger AC, Catalano PJ, Haller DG: Colon cancer survival is associated with decreasing ratio of metastatic to examined lymph nodes. J Clin Oncol 2005, 23:8706-870I 2.

2. Liang $H$, Wang XN, Wang BG, Pan Y, Liu N, Wang DC, Hao XS: Prognostic factors of young patients with colon cancer after surgery. World J Gastroenterol 2006, I 2: I 458- I 462.

3. Palmqvist R, Engaras B, Lindmark G, Hallmans G, Tavelin B, Nillson O, Hammarström S, Hafström L: Prediagnostic levels of carcinoembryonic antigen and CA 242 in colorectal cancer: a matched case-control study. Dis Colon Rectum 2003, 46:1538-1544.

4. Northover J: Carcinoembryonic antigen and recurrent colorectal cancer. Gut 1986, 27: I 17-122.

5. Carriquiry LA, Pineyro A: Should carcinoembryonic antigen be used in the management of patients with colorectal cancer. Dis Colon Rectum 1999, 42:921-929.

6. Duffy MJ: Carcinoembryonic antigen as a marker for colorectal cancer: is it clinically useful. Clin Chem 200I, 47:624-630.

7. Magnani JL, Steplewski Z, Koprowski H, Ginsburg V: Identification of the gastrointestinal and pancreatic cancer-associated antigen detected by monoclonal antibody $19-9$ in the sera of patients as a mucin. Cancer Res 1983, 43:5489-5492.

8. Chapman MA, Buckley D, Henson DB, Armitage NC: Preoperative carcinoembryonic antigen is related to tumour stage and long-term survival in colorectal cancer. $\mathrm{Br} J$ Cancer 1998, 78:1346-1349.

9. Morales-Gutierrez V, Vegh I, Colina F, Gomez-Camara A, Ignacio Landa J, Ballesteros D, Carreira PE, Enriquez-De-Salamanca R: Survival of patients with colorectal carcinoma: possible prognostic value of tissular carbohydrate antigen 19.9 determination. Cancer 1999, 86:1675-1681.

10. Reiter W, Stieber P, Reuter C, Nagel D, Lau-Warner U, Lamerz R: Multivariate analysis of the prognostic value of CEA and CA 19-9 serum levels in colorectal cancer. Anticancer Res 2000, 20:5195-5198.

II. Stelzner S, Hellmich G, Koch R, Ludwig K: Factors predicting survival in stage IV colorectal carcinoma patients after palliative treatment: a multivariate analysis. I Surg Oncol 2005, 15:2II-2I7.

12. Takahashi Y, Mai M, Nakazato H: Preoperative CEA and PPD values as prognostic factors for immunochemotherapy using PSK and 5-FU. Anticancer Res 2005, 25:1377-1384.

13. Safi F, Roscher R, Bittner R, Beger HG: The clinical relevance of tumor marker CEA, CA $19-9$ in regional chemotherapy for hepatic metastases of colorectal carcinoma. Int J Biol Markers 1988, 3:101-106.

14. Louhimo J, Carpelan-Holmström M, Alfthan H, Stenman UH, Jarvinen HJ, Haglund C: Serum HCG beta, CA 72-4 and CEA are independent prognostic factors in colorectal cancer. Int J Cancer 2002, 101:545-548.

15. Liotta LA, Stetler-Stevenson WG: Tumor invasion and metastasis: an imbalance of positive and negative regulation. Cancer Res I99I, 5 I (18 Suppl):5054s-5059s.

16. Premzl A, Turk V, Kos J: Intracellular proteolytic activity of cathepsin B is associated with capillary-like tube formation by endothelial cells in vitro. J Cell Biochem 2006, 97: I 230-1240.

17. Sloane BF: Cathepsin B and cystatins: evidence for a role in cancer progression. Semin Cancer Biol 1990, 1:137-152.
18. Murphy G, Atkinson S, Ward R, Garziloric J, Reynolds J]: The role of plasminogen activators in the regulation of connective tissue metalloproteinases. Ann NY Acad Sci 1992, 667: I-12.

19. Dano K, Behrendt N, Hoyer-Hansen G, Johnson M, Lund LR, Ploug M, Romer J: Plasminogen activations and cancer. Thromb Haemost 2005, 93:676-68I.

20. Krueger S, Kalinski T, Wolf H, Kellner U, Roessner A: Interactions between human colon carcinoma cells, fibroblasts and monocytic cells in coculture-regulation of cathepsin B expression and invasiveness. Cancer Lett 2005, 223:3। 3-322.

21. Cavallo-Medved D, Mai J, Dosescu J, Sameni M, Sloane BF: CaveolinI mediates the expression and localization of cathepsin B, pro-urokinase plasminogen activator and their cell-surface receptors in human colorectal carcinoma cells. J Cell Sci 2005 , I I 8:1493-1503.

22. Herszenyi L, Plebani M, Carraro P, De Paoli M, Di Mario F, Kusstatscher S, Rugge M, Cardin R, Naccarato R, Farinati F: Impaired fibrinolysis and increased protease levels in gastric and duodenal mucosa of patients with active duodenal ulcer. Am J Gastroenterol 1997, 92:843-847.

23. Herszenyi L, Hritz I, Pregun I, Sipos F, Juhasz M, Molnar B, Tulassay Z: Alterations of glutathione $S$-transferase and matrix metalloproteinase-9 expressions are early events in esophageal carcinogenesis. World J Gastroenterol 2007, I 3:676-682.

24. Plebani M, Herszenyi L, Cardin R, Roveroni G, Carraro P, De Paoli M, Rugge M, Nitti D, Naccarato R, Farinati F: Cysteine and serine proteases in gastric cancer. Cancer 1995, 76:367-375.

25. Plebani M, Herszenyi L, Carraro P, De Paoli M, Roveroni G, Cardin R, Tulassay Z, Naccarato R, Farinati F: Urokinase-type plasminogen activator receptor in gastric cancer: tissue expression and prognostic role. Clin Exp Metastasis 1997, 15:418-425.

26. Herszenyi L, Plebani M, Carraro P, De Paoli M, Roveroni R, Cardin R, Tulassay $Z$, Naccarato $R$, Farinati $F$ : The role of cysteine and serine proteases in colorectal cancer. Cancer 1999, 86: I|35- I| 42.

27. Farinati F, Herszenyi L, Plebani M, Carraro P, Cardin R, De Paoli M, Roveroni G, Rugge M, Nitti D, Naccarato R: Increased levels of cathepsin B and L, urokinase-type plasminogen activator and inhibitor type- $I$ as an early event in gastric carcinogenesis. Carcinogenesis 1996, I7:258I-2587.

28. Harbeck N, Alt U, Berger U, Krüger A, Thomssen C, Janicke F, Höfler $\mathrm{H}$, Kates RF, Schmitt M: Prognostic impact of proteolytic factors (urokinase-type plasminogen activator, plasminogen activator inhibitor $I$, and cathepsins $B, D$, and $L$ ) in primary breast cancer reflects effects of adjuvant systemic therapy. Clin Cancer Res 200I, 7:2757-2764.

29. Manders P, Tjan-Heijnen VC, Span PN, Grebenchtchikov N, Foekens JA, Beex LV, Sweep FCG]: Predictive impact of urokinase-type plasminogen activator:plasminogen activator inhibitor typeI complex on the efficacy of adjuvant systemic therapy in primary breast cancer. Cancer Res 2004, 64:659-664.

30. Harbeck N, Schmitt M, Paepke S, Allgayer H, Kates RE: Tumorassociated proteolytic factors UPA and PAI-I: critical appraisal of their relevance in breast cancer and their integration into decision-support algorithm. Crit Rev Clin Lab Sci 2007, 44:179-201.

31. Werle B, Kotzsch M, Lah TT, Kos J, Gabrijelcic-Geiger D, Spiess E, Schirren J, Ebert W, Fiehn W, Luther T, Magdolen V, Schmitt M, Harbeck N: Cathepsin B, plasminogenactivator-inhibitor (PAI-I) and plasminogenactivator-receptor (UPAR) are prognostic factors for patients with non-small cell lung cancer. Anticancer Res 2004, 24:4|47-4I6I.

32. Offersen BV, Pfeiffer P, Andreasen P, Overgaard J: Urokinase plasminogen activator and plasminogen activator inhibitor typeI in normal-cell lung cancer: relation to prognosis and angiogenesis. Lung Cancer 2007, 43:43-50.

33. Speleman L, Kerrebijn JD, Look MP, Meeuwis CA, Fockens JA, Berns EM: Prognostic value of plasminogen activator inhibitor- $I$ in head and neck squamous cell carcinoma. Head Neck 2007, 29:34I-350.

34. Dorn J, Harbeck N, Kates R, Magdolen V, Grass L, Soosaipillai A, Schalfeldt B, Diamandis EP, Schmitt M: Disease processes may be reflected by correlations among tissue kallikrein proteases but not proteolytic factors UPA and PAI- $I$ in primary ovarian carcinoma. Biol Chem 2006, 387: I I2I-III28.

35. Sier CFM, Verspaget HW, Griffioen G, Ganesh S, Vloedgraven JH Lamers CB: Plasminogen activators in normal tissue and car- 
cinomas of the human esophagus and stomach. Gut 1993, 34:80-85.

36. Iwamoto J, Mizokami Y, Takahashi K, Nakajima K, Ohtsubo T, Miura S, Narasaka T, Takeyama H, Omata T, Shimokobe K, Ito M, Takehara $H$, Matsuoka $T$ : Expressions of urokinase-type plasminogen activator, its receptor and plasminogen activator inhibitor-I in gastric cancer and effects of Helicobacter pylori. Scand J Gastroenterol 2005, 40:783-793.

37. Sakakibara T, Hibi K, Koike M, Fujiwara M, Kodera Y, Ito K, Nakao A Plasminogen activator inhibitor-I as a potential marker for the malignancy of gastric cancer. Cancer Sci 2006, 97:395-399.

38. Beyer BC, Heiss MM, Simon EH, Gruetzner KU, Babic R, Jauch KW, Schildberg FW, Allgayer H: Urokinase system expression in gastric carcinoma: prognostic impact in an independent patient series and first evidence of predictive value in preoperative biopsy and intestinal metaplasia specimens. Cancer 2006, 106: 1026-1035.

39. Sier CF, Vloedgraven HJM, Ganesh S, Griffioen G, Quax PH, Verheijen JH, Dooijewaard G, Welvaart K, Velde CJ van de, Lamers CB: Inactive urokinase and increased levels of its inhibitors type I in colorectal cancer liver metastasis. Gastroenterology 1994, 107:1449-1456.

40. Ganesh S, Sier CF, Heerding MM, van Krieken JH, Griffioen G, Welvaart $\mathrm{K}$, Velde $\mathrm{CJ}$ van de, Verheijen JH, Lamers CB, Verspaget HW: Contribution of plasminogen activators and their inhibitors to the survival prognosis of patients with Dukes's stage B and C colorectal cancer. Br J Cancer 1997, 75: I793-I80I.

4I. Adenis A, Huet G, Zerimech F, Hecquet B, Balduyck M, Peyrat JP: Cathepsin B, L, and D activities in colorectal carcinomas: relationship with clinical-pathological parameters. Cancer Lett 1995, 96:267-275

42. Talieri M, Papadopoulou S, Scorilas A, Xynopoulos D, Arnogianaki N Plataniotis G, Yotis J, Agnanti N: Cathepsin B and cathepsin D expression in the progression of colorectal adenoma to carcinoma. Cancer Lett 2004, 205:97-I06.

43. Troy AM, Sheahan K, Mulcahy HE, Duffy MJ, Hyland JM, O'Donoughe DP: Expression of cathepsin $B$ and $L$ antigen and activity is associated with early colorectal progression. Eur J Cancer 2004, 40:1610-1616.

44. Kim TD, Song KS, Li G, Choi H, Park HD, Lim K, Hwang BD, Yoon $\mathrm{WH}$ : Activity and expression of urokinase-type plasminogen activator and matrix metalloproteinases in human colorectal cancer. BMC Cancer 2006, 6:2II.

45. Obermeyer K, Krueger S, Peters B, Falkenberg B, Roessner A, Röcken C: The expression of low density lipoprotein receptor-related protein in colorectal carcinoma. Oncol Rep 2007, 17:361-367.

46. Nekarda H, Schmitt M, Ulm K, Wenninger A, Vogelsang H, Becker K, Roder JD, Fink U, Siewert JR: Prognostic impact of urokinasetype plasminogen activator and its inhibitor PAI-I in completely resected gastric cancer. Cancer Res 1994, 54:2900-2907.

47. Ganesh S, Sier CFM, Heerding MH, van Krieken JHJM, Griffioen G, Welwaart K, Velde Cl van de, Verheijen JH, Lamers CB, Verspaget $\mathrm{HW}$ : Prognostic value of the plasminogen activation system in patients with gastric carcinoma. Cancer 1996, 77: 1035-1043.

48. Abe J, Urano T, Konno H, Erhan Y, Tanaka T, Nishino N, Takada A Nakamura S: Larger and more invasive colorectal carcinoma contains larger amounts of plasminogen activator inhibitor type $I$ and its relative ratio over urokinase receptor correlates well with tumor size. Cancer 1999, 86:2602-26II.

49. Yang JL, Seetoo DQ, Wang Y, Ranson M, Berney CR, Ham JM, Russe PJ, Crowe PJ: Urokinase-type plasminogen activator and its receptor in colorectal cancer: independent prognostic factors of metastasis and cancer-specific survival and potential therapeutic targets. Int J Cancer 2000, 89:43I-439.

50. Sakakibara T, Hibi K, Koike M, Fujiwara M, Kodera Y, Ito K, Nakao A: Plasminogen activator inhibitor-I as a potential marker for the malignancy of colorectal cancer. $\mathrm{Br}$ J Cancer 2005, 93:799-803.

5I. Hirano T, Manabe T, Takeuchi S: Serum cathepsin B levels and urinary excretion of cathepsin B in cancer patients with remote metastasis. Cancer Lett 1993, 70:3|-44.

52. Huber K, Kirchheimer C, Sedlmayer A, Bell C, Ermler D, Binder BR: Clinical value of determination of urokinase-type plasminogen activator antigen in plasma for detection of colorectal cancer: comparison with circulating tumor-associated anti- gens CA 19-9 and carcinoembryonic antigen. Cancer Res 1993, 53:1788-1793.

53. Kos J, Nielsen HJ, Krasovec M, Christensen IJ, Cimerman N, Stephens RW, Brünner N: Prognostic values of cathepsin B and carcinoembryonic antigen in sera of patients with colorectal cancer. Clin Cancer Res 1998, 4: I5 I I- I5 I6.

54. Nielsen HJ, Christensen IJ, Sorensen S, Moesgaard F, Brunner N: Preoperative plasma plasminogen activator inhibitor type- $I$ and serum C-reactive protein levels in patients with colorectal cancer. The RANX05 Colorectal Cancer Study Group. Ann Surg Oncol 2000, 7:617-623.

55. Sebdzda T, Saleh Y, Gburek J, Warwas M, Andrzejak R, Siewinski M, Rudnicki J: Total and lipid-bound plasma sialic acid and diagnostic markers in colorectal cancer patients: correlation with cathepsin B expression in progression to Dukes stage. Exp Ther Oncol 2006, 5:223-229.

56. Turnbull RB, Kyle K, Watson FR, Spratt J: Cancer of the colon: the influence of the no-touch isolation on the survival rates. Ann Surg 1967, 166:420-427.

57. De Bruin PAF, Griffioen G, Verspaget HW, Verheijen JH, Lamers $\mathrm{CBHW}$ : Plasminogen activators and tumor development in the human colon: activity levels in normal mucosa, adenomatous polyps and adenocarcinomas. Cancer Res 1987, 47:4654-4657.

58. Duffy MJ, van Dalen A, Haglund C, Hansson L, Holinski-Feder E, Klapdor R, Lamerz R, Peltomaki P, Sturgeon C, Topolcan O: Tumor markers in colorectal cancer: European Group on tumour Markers (EGTM) guidelines for clinical use. Eur J Cancer 2007. 43:1348-1360.

59. Locker GY, Hamilton S, Harris J, Jessup JM, Kemeny N, Macdoland JS, Somerfield MR, Hayes DF, Bast RC Jr: ASCO 2006 update of recommendations for the use of tumor markers in gastrointestinal cancer. J Clin Oncol 2006, 24:53/3-5327.

\section{Pre-publication history}

The pre-publication history for this paper can be accessed here:

\section{http://www.biomedcentral.com/1471-2407/8/194/pre} pub
Publish with Bio Med Central and every scientist can read your work free of charge

"BioMed Central will be the most significant development for disseminating the results of biomedical research in our lifetime. "

Sir Paul Nurse, Cancer Research UK

Your research papers will be:

- available free of charge to the entire biomedical community

- peer reviewed and published immediately upon acceptance

- cited in PubMed and archived on PubMed Central

- yours - you keep the copyright

Submit your manuscript here:

http://www.biomedcentral.com/info/publishing_adv.asp
BioMedcentral 